\title{
A aplicação da tecnologia SIG na definição de parâmetros urbanísticos: a caracterização habitacional de assentamentos precários em um contexto educacional
}

The application of GIS technology in the definition of urban parameters: the housing characterization of precarious settlements in an educational context

Isabelle de Lima Almeida

Universidade de Fortaleza isabelle.almeida@edu.unifor.br

Marília Melo Mendonça

Universidade de Fortaleza

mmelomendonca@gmail.com
Maria Luiza Rodrigues Gurgel da Silva
Universidade de Fortaleza
malu.rgs@gmail.com

\author{
Mariana Saraiva de Melo Pinheiro \\ Universidade de Fortaleza \\ mariana.saraivamp@edu.unifor.br
}

\author{
Camila Rodrigues Aldigueri \\ Centro Universitário Christus \\ camila.aldigueri@gmail.com
}

\section{Resumo}

Este artigo apresenta a experiência do uso da tecnologia SIG (Sistema de Informação Geográfica) no contexto educacional da disciplina de Ateliê VI do curso de graduação em Arquitetura e Urbanismo da Universidade de Fortaleza. Tendo como finalidade a definição de parâmetros urbanísticos de ocupação do solo para a elaboração de planos de regularização urbanística e fundiária, utilizou-se o geoprocessamento no estudo das características habitacionais da comunidade do Caça e Pesca, localizada em Fortaleza. A relevância do tema do artigo deve-se à importância de trabalhar em sala de aula a regularização 


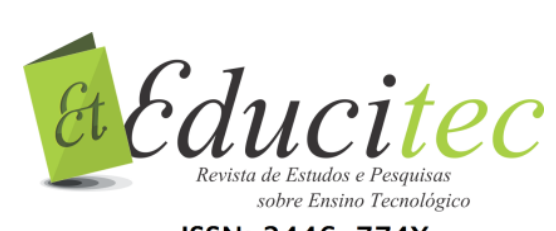

ISSN: $2446-774 X$

urbanística e fundiária de assentamentos precários através de suas características morfológicas. Nesse sentido, o uso de tecnologias de georreferenciamento mostra-se benéfico à sistematização dos dados coletados. Por meio do SIG, possibilita-se a abordagem das mais distintas variáveis urbanísticas, o que torna o trabalho de levantamento de dados mais aprofundado e condizente com a realidade encontrada na área de estudo, que apresenta relevantes diferenças em relação aos parâmetros de ocupação da cidade formal. Este artigo, portanto, apresenta uma breve revisão bibliográfica de temas como a questão habitacional e as tecnologias de georreferenciamento, assim como o relato da experiência do uso do SIG na atividade de caracterização habitacional no contexto da disciplina supramencionada.

Palavras-chave: Questão Urbana. Problemas Habitacionais. Tecnologia e Didática.

\section{Abstract}

This research presents an experience of the use of GIS (Geographic Information System) under an educational approach in the class of Ateliê VI of the course of Architecture and Urbanism at the University of Fortaleza. As this work aims to define technical urban planning parameters related to the land occupation and to elaborate plans of land regulation, the geoprocessing played a relevant role on the studies of the habitational characteristics at the community of Caça e Pesca, located in the city of Fortaleza. The importance of this theme relies on the need of the students to work with urban and land regulation through the morphological characteristics of human settlements. Thus, the use of the technology of geographic information shows benefits to the classification of the data collected. Through the GIS, it becomes possible to work with an approach that considers different urban situations, making the work of data collection more efficient and precise to the local context, which differs to the urban parameters of the formal city. The research counts with three main steps: literature survey about the habitational issue and the geographic technology; evaluation of the use of GIS through the work and projects developed by students; and collection of students' experiences, which highlighted the strategies and challenges faced on the rolling basis.

Key words: Urban Issues. Housing Problems. Technology and Didactics.

\section{Introdução}

Este artigo tem como objetivo apresentar a experiência do uso da tecnologia SIG (Sistema de Informação Geográfica) numa disciplina de graduação em Arquitetura e Urbanismo. Integrante do 8 $^{\circ}$ semestre da grade curricular deste curso na Universidade de Fortaleza (UNIFOR), a disciplina de Ateliê VI tem como temática central a questão da Habitação de Interesse Social (HIS). Tal conteúdo é abordado em sala de aula através do estudo de um assentamento precário da 


\section{Eteducitec \\ ISSN: $2446-774 X$}

capital cearense definido como Zona Especial de Interesse Social (ZEIS) pelo Plano Diretor Participativo de Fortaleza (PDP-FOR).

A disciplina encontra-se estruturada em três etapas distribuídas ao longo do período de um semestre letivo: diagnóstico, plano e projeto. Já a etapa de diagnóstico, por sua vez, encontra-se dividida em exercícios de estudo que abrangem temas como: condicionantes legais; condicionantes ambientais (como sistema hídrico e vegetação); espaços livres; mobilidade; uso do solo; infraestrutura urbana, características socioeconômicas e características habitacionais. Este último exercício e seus rebatimentos na etapa de elaboração do plano é o objeto de análise do presente artigo.

O texto aqui apresentado foi desenvolvido no contexto da experiência de monitoria acadêmica das autoras, vinculadas ao Programa de Monitoria Voluntária da Universidade de Fortaleza, sob orientação da Profa. Dra. Camila Rodrigues Aldigueri. $O$ relato trata do acompanhamento das práticas desenvolvidas em sala de aula durante o semestre de 2018.1, tendo como objeto de estudo o exercício da caracterização habitacional de um setor da comunidade do Caça e Pesca, localizada no bairro da Praia do Futuro II, litoral leste da cidade de Fortaleza (Figura 1). O Caça e Pesca, comunidade cuja origem da ocupação data da década de 1940 (LOPES FILHO et al., 2018), caracteriza-se pelas marcantes dinâmicas ambientais de seu entorno, que envolve a foz do Rio Cocó, com suas dunas e manguezais. Desde 2009, a comunidade encontra-se demarcada pelo PDP-FOR como uma ZEIS do tipo I.

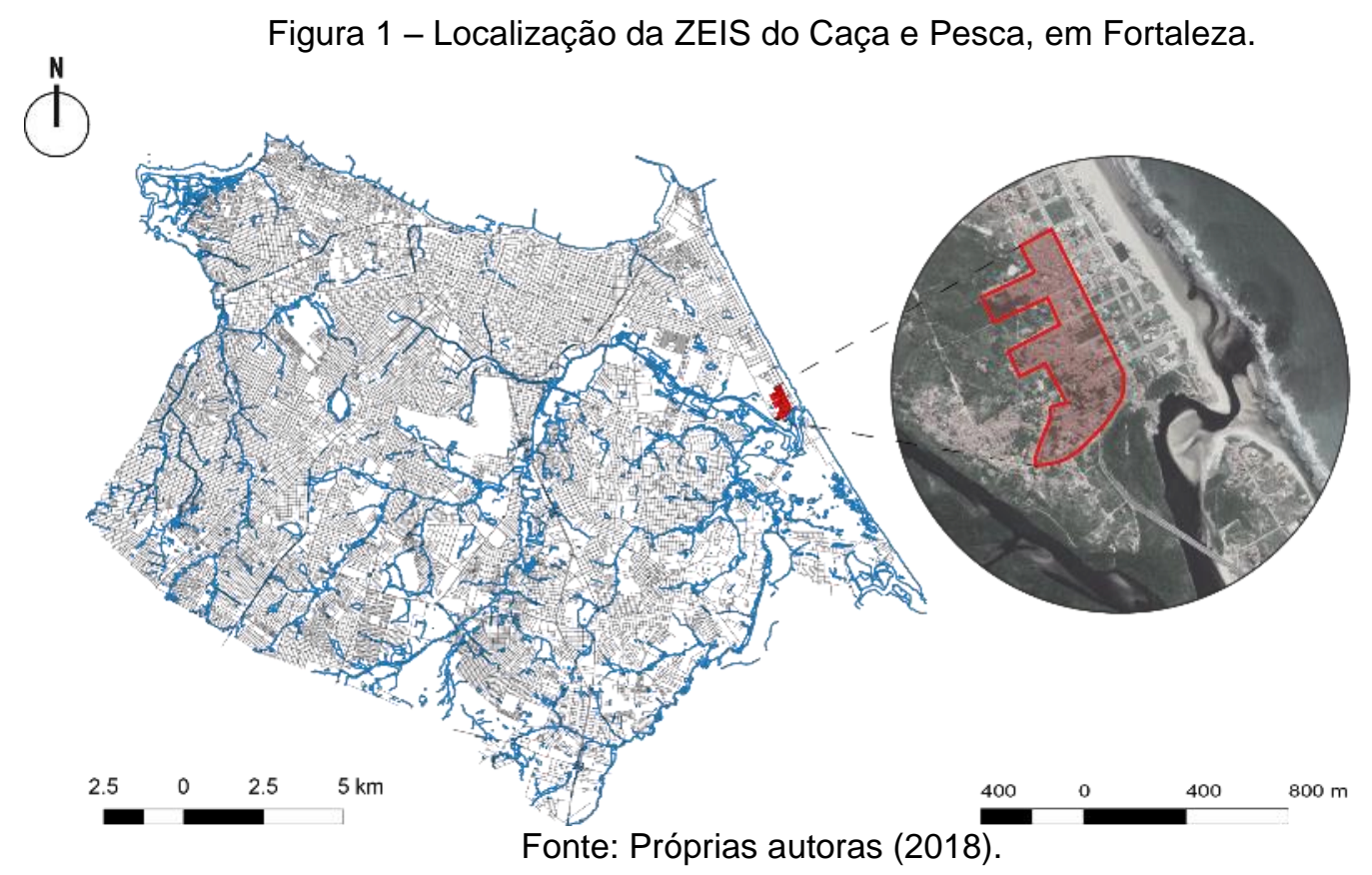

Aponta-se que a Figura 1 foi constrúida com base em imagem de satélite disponível no Google Earth (2018) e base cartográfica disponibilizada pela Prefeitura Municipal de Fortaleza (2010).

O exercício acadêmico de estudo das características habitacionais da comunidade do Caça e Pesca contou com o auxílio da tecnologia SIG. Por meio desta, são georreferenciadas características de ocupação do solo a serem 


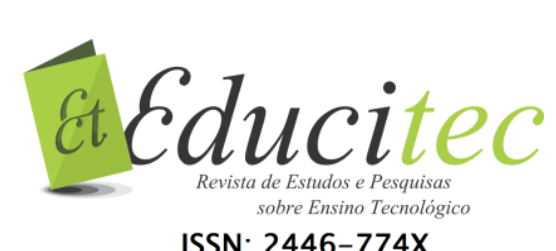

utilizadas na definição de parâmetros urbanísticos dos planos de regularização urbanística desenvolvidos em equipe durante a disciplina de Ateliê VI.

A relevância da elaboração de planos de intervenção em um contexto educacional deve-se à necessidade de que o processo de regularização urbanística e fundiária em áreas demarcadas como ZEIS seja conduzido por meio de um Plano de Urbanização e Regularização Fundiária, que deve ser elaborado de acordo com os objetivos do PDP-FOR. Em Fortaleza, o processo de regulamentação das ZEIS teve início em 2018. Dentre as 45 ZEIS de tipo I demarcadas em Fortaleza, 10 destas foram definidas como prioritárias, sendo o Caça e Pesca uma das escolhidas (FEITOSA, 2018). O recente processo de regulamentação conta com a elaboração dos Planos Integrados de Regularização Fundiária (PIRFs) para cada ZEIS, desenvolvidos através de convênios com as Instituições de Ensino Superior (IESs) do Ceará. Neste contexto, coube à Universidade de Fortaleza a elaboração do PIRF da ZEIS do Caça e Pesca.

Considerando um contexto em que as metrópoles brasileiras contam com um aparato de "padrões modernistas detalhados de construção e ocupação do solo" ao mesmo tempo em que "convivem com a gigantesca cidade ilegal onde a contravenção é regra" (MARICATO, 2003, p. 153), a urbanização e a regularização fundiária em áreas socioambientalmente vulneráveis surge como uma estratégia de democratização do espaço urbano e de redução do nível de segregação residencial (SOUZA, 2008). Estas áreas, marcadas pela autoconstrução das formas de ocupação do solo, revelam parâmetros urbanísticos e edilícios em desacordo aos definidos na legislação urbana, tendo em vista a problemática da falta de acesso de boa parte da população ao mercado privado residencial legal (MARICATO, 2003). No contexto local, Fortaleza conta com um total de $32 \%$ de seus domicílios localizados em assentamentos precários, caracterizados "pela inadequação de suas habitações e pela irregularidade no acesso à terra" (FORTALEZA, 2013, p. 27). Destes, $74 \%$ correspondem à tipologia favela.

Nesse sentido, a formação de arquitetos urbanistas conscientes e preparados para atuar profissionalmente na urbanização e na regularização de assentamentos precários torna-se essencial para lidar com essa realidade, visto que as ações de regularização fundiária tratam-se de medidas que reconhecem a expressiva irregularidade da maioria das cidades brasileiras e contribuem para sanar o déficit habitacional qualitativo. Todavia, conforme alerta Alfonsin (2005), essas ações referem-se a medidas paliativas e não preventivas, pois a regularização fundiária, por si só, não é capaz de resolver as causas estruturais do surgimento e expansão dos assentamentos precários e irregulares.

Considerando esse contexto, o uso da tecnologia SIG apresenta-se como uma ferramenta relevante no auxílio da produção de diagnósticos e planos de intervenção, sendo esta uma aliada na estratégia de aproximação do aluno de graduação com a realidade dos assentamentos precários. A partir do exercício acadêmico de estudo das características habitacionais da área de estudo com o auxílio do georreferenciamento, espera-se que a produção de planos de urbanização possa estar baseada em tomadas de decisões mais conscientes 


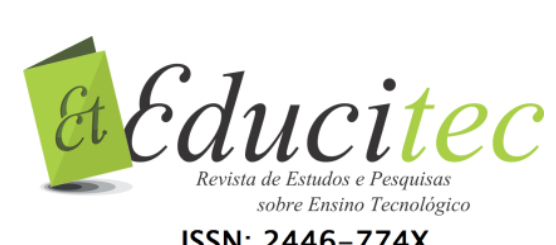

ISSN: $2446-774 X$

dos impactos socioespaciais dos parâmetros urbanísticos propostos para a comunidade e seu entorno. Nesse sentido, a prática de trabalhos acadêmicos relacionados à questão da regularização e urbanização de assentamentos precários mostra-se pertinente à formação de futuros profissionais da Arquitetura e do Urbanismo capazes de atuar neste campo de trabalho em implantação no cenário local.

Este artigo, inicialmente, apresenta uma breve revisão bibliográfica abordando temas relativos à questão habitacional e à tecnologia SIG. Enfatiza-se, especificamente, as ZEIS como um instrumento de flexibilização de parâmetros no processo de regularização fundiária, além das vantagens do uso da tecnologia SIG e da sua aplicabilidade no contexto de assentamentos precários tecnologia SIG. Posteriormente, inicia-se o relato da experiência do uso do SIG na atividade de caracterização habitacional no contexto da disciplina supramencionada. A apresentação da experiência em sala de aula se dá através da análise de alguns trabalhos desenvolvidos pelos alunos e da exposição dos resultados de um questionário de avaliação do exercício elaborado pelas autoras, que levou em consideração a compreensão da ferramenta e o seu uso pelos alunos, diante do objetivo de alcançar a caracterização habitacional a formulação de um Plano de Regularização Urbanística e Fundiária para o assentamento precário objeto de estudo. Por fim, apresentam-se as considerações finais acerca dos aspectos positivos e negativos do exercício desenvolvido em sala de aula.

\section{ZEIS e a flexibilização de parâmetros urbanísticos para fins de regularização urbanística e fundiária}

O desigual processo de urbanização no Brasil, marcado por uma gigantesca exclusão territorial, acarretou na produção de espaços de moradia informal, sem financiamento público ou acompanhamento de profissionais como arquitetos e engenheiros (MARICATO, 2003). Estes espaços, caracterizados predominantemente pela ilegalidade fundiária e urbanística, e, por vezes, pela precariedade edilícia e urbana, estão vinculados a problemas macroestruturais da urbanização brasileira, como: a importância da propriedade fundiária numa sociedade patrimonialista; o processo de industrialização marcado pela precarização e informalização das relações de trabalho; o mercado privado residencial legal restrito; o Estado inoperante e a aplicação arbitrária da lei (CARDOSO, 2007; MARICATO, 2011).

Considerando um contexto metropolitano de disputa pela terra urbana por parte do mercado imobiliário, as populações de baixa renda acabam por instalar-se em áreas dispensadas pelos interesses do mercado privado, principalmente em terras públicas, áreas em regiões desvalorizadas, ou áreas de proteção ambiental cuja ocupação legal é inviabilizada pela legislação vigente. Nesse sentido, avança a segregação socioambiental, "uma das faces mais importantes da desigualdade social e parte promotora da mesma" (MARICATO, 2003, p. 152), visto que: 


\title{
Ceducitec \\ ISSN: $2446-774 X$
}

À dificuldade de acesso aos serviços e infra-estrutura urbanos (transporte precário, saneamento deficiente, drenagem inexistente, dificuldade de abastecimento, difícil acesso aos serviços de saúde, educação e creches, maior exposição à ocorrência de enchentes e desmoronamentos etc.) somam-se menos oportunidades de emprego (particularmente do emprego formal), menos oportunidades de profissionalização, maior exposição à violência (marginal ou policial), discriminação racial, discriminação contra mulheres e crianças, difícil acesso à justiça oficial, difícil acesso ao lazer. A lista é interminável. (MARICATO, 2003, p. 152).

Nesse contexto, a regularização fundiária surge como uma ferramenta de segurança jurídica da posse da terra urbana, que busca reduzir o nível de disparidade socioeconômico-espacial intraurbana (SOUZA, 2003). O aparato legal de democratização do acesso à terra urbana inicia-se com a introdução do capítulo da política urbana na Constituição de 1988 e com o Estatuto da Cidade de 2001, que estabelecem "instrumentos urbanísticos e jurídicos fundamentais para reduzir o quadro de exclusão sócio-territorial crescente no país" (GONÇALVES; FREITAS; RIBEIRO, 2012, p. 3). Em 2003, formula-se a Política Nacional de Regularização Fundiária de áreas urbanas e, no ano seguinte, é aprovada a Política Nacional de Habitação, "trazendo uma concepção de desenvolvimento urbano integrado, no qual a habitação não se restringe à casa, mas incorpora o direito à infraestrutura, saneamento ambiental, mobilidade e transporte coletivo, equipamentos e serviços urbanos e sociais" (GONÇALVES; FREITAS; RIBEIRO, 2012, p. 3). É nesse contexto da década de 2000 que se inicia a demarcação de Zonas Especiais de Interesse Social (ZEIS) nos planos diretores municipais em escala nacional.

Sendo assim, o entendimento legal passa a ser não apenas de garantia de posse da terra urbana, mas também de provimento da infraestrutura urbana básica, combatendo a segregação territorial através da urbanização de assentamentos integrada ao processo de regularização fundiária. Dessa forma, viabiliza-se a permanência de populações de baixa renda em seus locais de origem, resultando em integração física e social do tecido urbano dos assentamentos precários com o restante da cidade.

Em Fortaleza, as ZEIS têm sua demarcação realizada por meio do Plano Diretor Participativo (PDP-FOR) de 2009, que as define como:

\begin{abstract}
(...) porções do território, de propriedade pública ou privada, destinadas prioritariamente à promoção da regularização urbanística e fundiária dos assentamentos habitacionais de baixa renda existentes e consolidados e ao desenvolvimento de programas habitacionais de interesse social e de mercado popular nas áreas não edificadas, não utilizadas ou subutilizadas, estando sujeitas a critérios especiais de edificação, parcelamento, uso e ocupação do solo (FORTALEZA, 2009, p. 16).
\end{abstract}

Sendo assim, três categorias de ZEIS são instituídas em Fortaleza com o PDPFOR: as ZEIS do tipo I, relativas a assentamentos irregulares com ocupação desordenada já consolidados; as ZEIS do tipo II, concernentes aos loteamentos clandestinos ou irregulares ocupados por população de baixa renda e aos conjuntos habitacionais degradados; e, por fim, as ZEIS do tipo III, que 


\section{Educitec \\ ISSN: $2446-774 X$}

resguardam vazios dotados de infraestrutura urbana, destinando-os ao reassentamento de populações de baixa renda (FORTALEZA, 2009).

O PDP-FOR ressalta a necessidade de regularização urbanística e fundiária de assentamentos precários, processo que deve ser conduzido por meio de um Plano de Urbanização e Regularização Fundiária. Tal plano deve conter "objetivos e metas a serem alcançadas com a intervenção (...); diretrizes e ações a serem tomadas para alcançar os objetivos e cumprir as metas; e por fim os novos parâmetros e índices a serem utilizados no projeto" (BRASIL; ALDIGUERI, 2014, p. 5-6). Os parâmetros dizem respeito à permissão construtiva em determinado lugar, estabelecendo valores que se revertem em formas de ocupação do solo. No caso das ZEIS, tais parâmetros podem ser modificados com o objetivo de atender à realidade morfológica de cada assentamento, já que tais áreas "constituem-se como espaços de irregularidade urbanística, encontrando-se à margem dos parâmetros e índices urbanísticos estabelecidos por lei" (BRASIL; ALDIGUERI, 2014, p. 10-11).

Ao regularizar urbanisticamente um determinado assentamento precário, tornase necessária a definição de parâmetros construtivos em conformidade com a realidade local, que, de forma geral, possui características habitacionais em desconformidade com a legislação vigente. Tal característica dos assentamentos precários resulta da sua forma "espontânea" de construir. Assim, busca-se flexibilizar os índices, o que possibilita garantir a permanência das residências, desde que se permita também assegurar as condições mínimas de habitabilidade. Caso fossem aplicados os parâmetros indicados por meio de zoneamento estabelecido pela legislação urbanística vigente, as residências seriam removidas praticamente em sua totalidade, e suas famílias ocupantes teriam de ser reassentadas.

\section{A tecnologia SIG e a sua aplicabilidade em assentamentos precários}

Surgido na década de 1950, o Sistema de Informação Geográfico (SIG) é um instrumento computacional que permite relacionar, armazenar, gerar, visualizar e analisar diversos níveis de dados georreferenciados, ou seja, dados que possuem atributos relacionados à sua localização dentro de um sistema de coordenadas (LISBOA FILHO, 1996). Tal potencial analítico possibilita o aprofundamento do estudo de assentamentos precários, visto que, por meio do SIG, permite-se o desenvolvimento de um banco de dados contendo informações georreferenciadas relativas às características habitacionais de cada unidade habitacional.

Tratando-se de regularização urbanística e fundiária, a precisão das informações acerca de características edilícias como tamanho do lote, recuos e testadas, entre outras, influencia a definição de parâmetros urbanísticos de ocupação do solo. Por sua vez, os parâmetros impactam as ações contidas nos planos de regularização, como a questão do reassentamento ou permanência de determinada unidade habitacional. 


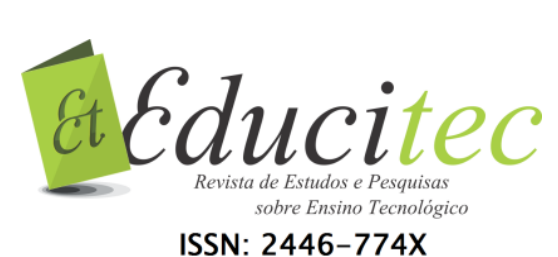

No caso da elaboração de planos de regularização urbanística e fundiária que não contam com o auxílio da tecnologia SIG, a implementação de ações vinculadas ao plano apresenta desafios relacionados à precisão de informações. É importante ressaltar que tal falta de informação exata gera "custos financeiros e administrativos para todas as políticas urbanas" (FREITAS; LIMA, 2012, p. 2), e que este problema pode também interferir no ordenamento territorial urbano, visto que é com base nesses estudos que intervenções urbanas e regularizações jurídicas da posse são feitas.

A exemplo dessa dificuldade encontrada em casos em que a tecnologia SIG não é utilizada, apresenta-se um estudo realizado por Freitas e Lima (2012). O trabalho desenvolvido pelas autoras descreve como o processo de regularização fundiária de um assentamento precário classificado como ZEIS na cidade de Fortaleza foi conduzido em 2005. O cadastro territorial foi realizado por meio do software Access e incluiu 1.450 imóveis, identificados a partir do endereço do imóvel e do nome do posseiro. As autoras ressaltam que a falta de integração entre as informações socioeconômicas do banco de dados com as informações do limite do lote "torna o processo de regularização fundiário mais lento" (FREITAS; LIMA, 2012, p. 3-4).

O SIG, por sua vez, apresenta a vantagem da visualização instantânea das modificações na cartografia, visto que tal tecnologia funciona por meio de atualização contínua. Esta característica é de grande relevância no estudo de assentamentos precários e na proposição de planos de regularização urbanística e fundiária, pois durante o processo de definição de parâmetros é importante perceber o rebatimento de cada critério na realidade. Assim, pode-se identificar, por exemplo, quantas e quais casas serão removidas por não atenderem aos parâmetros definidos, bem como qualquer outro indicador socioeconômico e espacial que não permita 0 atendimento das condições mínimas de habitabilidade.

Enquanto por meio da utilização do SIG é possível, por exemplo, categorizar e graduar informações a partir de valores à escolha do usuário, o método "tradicional" - aquele cujos mapas são provenientes da atividade de desenho - oferece menos possibilidades e agilidade de análise. Assim, conforme destacam Kleiner e Meneguette (2002), diante do maior desafio dos sistemas de informações atuais, a manutenção de dados, o SIG alcançou relevante notoriedade em oferecer agilidade e facilidade nessa organização, não importando se a base de dados é de grande ou pequeno porte.

É relevante ressaltar, entretanto, que a variedade de funções e de possibilidades ofertadas pela plataforma exige do usuário uma compreensão clara da especificidade das informações com as quais trabalha. Além da manipulação de dados, é necessário que o usuário tenha conhecimento acerca da estruturação do armazenamento dos dados na base, assim como das técnicas de atualização e de gerenciamento desta base e das aplicações e análises possíveis de serem realizadas (KLEINER; MENEGUETTE, 2002). Ressalta-se, ainda, que a tecnologia SIG ganha maior confiabilidade quando associada a visitas in loco para a aferição do levantamento do banco de dados. Dessa forma, a coleta de informações expande-se para além da leitura de imagens e cartografias digitais. 


\section{Educitec}

ISSN: $2446-774 X$

\section{O uso do SIG na caracterização habitacional e definição de parâmetros: a experiência da disciplina de Ateliê VI}

A atividade de caracterização habitacional, objeto de análise deste artigo, integra a etapa de diagnóstico da comunidade e destaca-se como o principal momento de aproximação do aluno de Ateliê VI com a realidade estudada. Por meio da caracterização habitacional, o aluno passa a estar em contato com formas de ocupação do solo distintas dos padrões concebidos para a cidade formal. Sendo assim, este momento é de grande importância para que, na etapa de projeto, as equipes possam propor intervenções em conformidade com a realidade morfológica da comunidade objeto de estudo.

A atividade acontece após o momento de visita a campo, e está fundamentada, principalmente, na leitura do texto "Estética das favelas", de autoria de Paola Jacques (2001). O texto apresenta as dimensões culturais, artísticas e estéticas da favela explicadas através das figuras conceituais de "fragmento", "labirinto" e "rizoma". Dessa maneira, o aluno passa a compreender os processos "espontâneos" e "orgânicos" da formação espacial da comunidade objeto de estudo (JACQUES, 2001), analisando, assim, a aplicação de tais conceitos na realidade local a partir da experiência espacial da favela, sendo esta proporcionada pela visita a campo.

A atividade proposta busca, portanto, reconhecer índices e padrões recorrentes da ocupação da comunidade estudada. Esta etapa leva à identificação das características formais essenciais à identidade local, sendo estas fundamentais na definição de novos parâmetros urbanísticos de ocupação do solo. Complementarmente, estabelecem-se ações integrantes do Plano de Urbanização e Regularização, tais como as prioridades para reassentamento, melhoria habitacional e moradias a serem consolidadas. Nesse sentido, a caracterização habitacional é trabalhada como uma forma de identificar inadequações habitacionais.

A tecnologia SIG aplica-se à atividade da caracterização habitacional através da sistematização de dados sobre as unidades habitacionais existentes na comunidade que, por sua vez, são levantadas pelos alunos a partir de medições em campo ou por meio de bases cartográficas e imagens de satélite. Após a coleta das características das unidades habitacionais, os alunos alimentam o banco de dados elaborado coletivamente em sala de aula, que contém as seguintes informações: materiais de construção, existência ou não de garagem, formas de acesso ao lote, quantidade de famílias, área do lote, área construída, testada, gabarito, recuos, taxa de ocupação e taxa de permeabilidade. Alguns índices são calculados com o auxílio da tecnologia SIG a partir de áreas já levantadas, como no caso das taxas de permeabilidade e de ocupação, que são obtidas a partir de dados referentes às áreas construída e do lote. Nesse processo, utiliza-se o software QGIS, que, por meio de shapes georreferenciados, possibilita a construção de um banco de dados através do preenchimento da tabela de atributos com os dados requisitados. Toda a atividade é acompanhada e auxiliada pela equipe pedagógica da disciplina formada por professoras e monitoras, que orientam o trabalho através de roteiro 


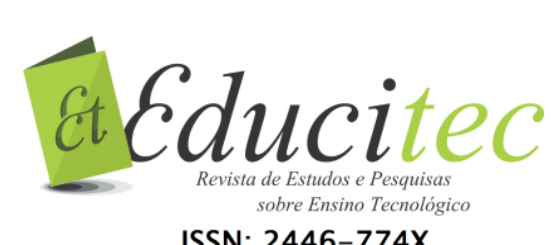

ISSN: $2446-774 X$

de trabalho e manual de uso do QGIS especificamente elaborados para a atividade.

O uso de tal metodologia representa um avanço em relação aos semestres anteriores, quando a tecnologia SIG não era aplicada, ou utilizada apenas parcialmente. No caso do semestre 2017.1, que teve como área de estudo a comunidade do Papoco, localizada na região oeste de Fortaleza, a atividade de caracterização habitacional restringiu-se ao levantamento de dados como área do lote, gabarito, testada e materiais de construção. Além disso, a sistematização desses dados se deu de forma desvinculada de tabelas capazes de cruzar diferentes informações, utilizando apenas softwares gráficos (tais como CorelDRAW, AutoCAD, Adobe Photoshop, entre outros) como forma de representação espacializada das informações levantadas. Além da grande quantidade de tempo empregada na produção de hachuras, linhas, contornos e outros elementos gráficos, a metodologia não se mostrava flexível à possibilidade de alteração dos aspectos analisados. A modificação de qualquer representação gráfica exigia, portanto, uma nova atividade de desenho. Sendo assim, tal metodologia mostra-se ineficiente frente à simulação de cenários possibilitada pela tecnologia SIG, tornando a tomada de decisões sobre os parâmetros para o Plano de Urbanização e Regularização Fundiária bastante limitada e por vezes imprecisa.

Já no semestre de 2017.2, que teve como área de estudo a comunidade do Poço da Draga, localizada na região histórica do antigo porto de Fortaleza em seu litoral central, a tecnologia SIG foi aplicada desde o início da disciplina, sendo utilizada tanto no desenvolvimento de trabalhos relacionados ao tema da paisagem quanto no exercício de caracterização das unidades habitacionais. Nesse processo de implementação da tecnologia SIG, diversos alunos encontraram dificuldades por conta do desconhecimento das ferramentas de softwares como o QGIS. No entanto, com o avançar dos trabalhos, o uso do SIG mostrou-se vantajoso pela sua capacidade de sistematização e de georreferenciamento das informações levantadas, além da facilidade de simulação de diversos cenários de aplicação de novos parâmetros urbanístico a partir do banco de dados de características habitacionais construído coletivamente pelos alunos em sala de aula.

Quanto ao semestre de 2018.1, período cuja experiência é o enfoque de análise deste artigo, a tecnologia SIG foi apresentada aos alunos através de aulas expositivas vinculadas ao manual de uso do software QGIS desenvolvido pela equipe pedagógica da disciplina, além do acompanhamento constante durante o período de realização do exercício tanto por parte das professoras quanto pelas monitoras. A atividade consistiu na criação de um banco de dados com as características habitacionais de uma determinada área da comunidade do Caça e Pesca. Nesse processo, cada equipe ficou responsável por um dos setores da comunidade definidos pelas monitoras. Ao final dessa etapa, as equipes comunicavam-se entre si para realizar a junção das tabelas. $O$ resultado final desse exercício pode ser visto na Figura 2, que mostra alguns dos mapas produzidos por uma equipe, utilizando como critérios de avaliação as áreas dos lotes, as áreas construídas, materiais de construção empregados e os tipos de vias de acesso. Esses mapas, em conjunto com outros produzidos sobre taxas 


\section{Edecitec \\ iss: $246-7.72 x$}

de ocupação e permeabilidade, recuos, alturas, pavimentos e testadas, permitiram identificar inadequações habitacionais. Posteriormente, as informações foram utilizados na definição das unidades habitacionais a serem reassentadas, consolidadas e melhoradas (Figura 3), assim como na proposição dos novos parâmetros urbanísticos integrantes da proposta de Plano de Regularização Urbanística e Fundiária da ZEIS elaborada por cada equipe.

Figura 2 - Espacialização de dados realizada por uma equipe por meio do software QGIS acerca das áreas do lote, áreas construídas, materiais de construção empregados e os tipos de vias de acesso das unidades habitacionais da comunidade do Caça e Pesca

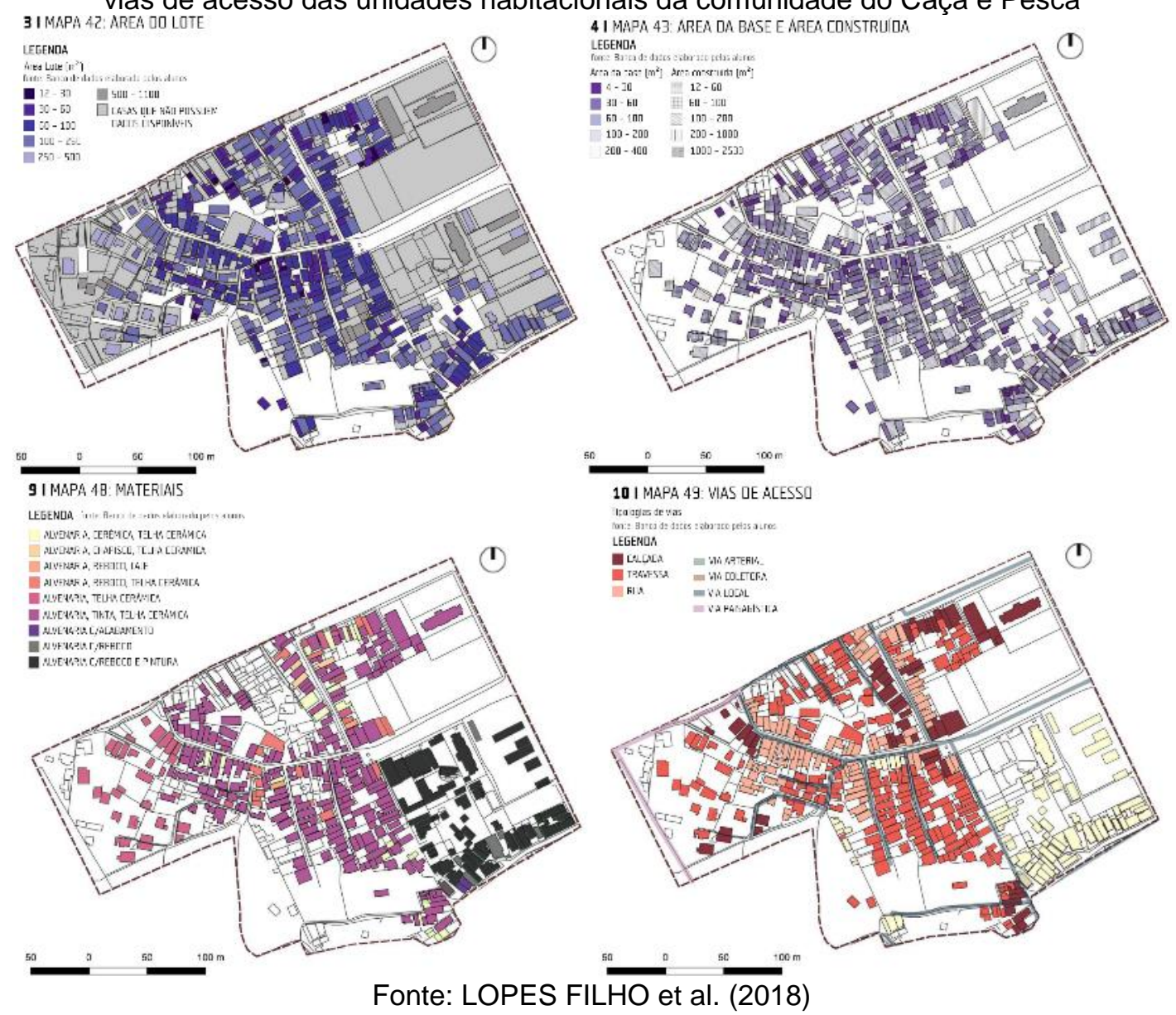

Os mapas desenvolvidos pelos alunos, como os apresentados pela Figura 2, serviram de auxílio para a compreensão da conformação espacial da comunidade. No mapa relativo à área do lote, por exemplo, foi visto que as casas com menor área encontram-se localizadas na parte central e mais adensada do Caça e Pesca. A gradação de cores permite a compreensão imediata das regiões mais delicadas do local de estudo. Além disso, foi identificado que a maior parte das vias eram locais, sendo a maioria destas da tipologia travessa. Quanto aos materiais de construção utilizados nas residências, identificou-se que a maior parte destas encontram-se executadas em alvenaria, com ou sem acabamento. Ao final, como mostrado na Figura 3, a equipe em questão utilizou como critério de definição de ações as características habitacionais de tamanho do lote, testada e altura, além de outros motivos relativos à questões urbanísticas. 
ISSN: $2446-774 X$

Figura 3 - Proposta de uma equipe para as unidades habitacionais a serem reassentadas, consolidadas e melhoradas, com as justificativas de acordo com as inadequações habitacionais encontradas.

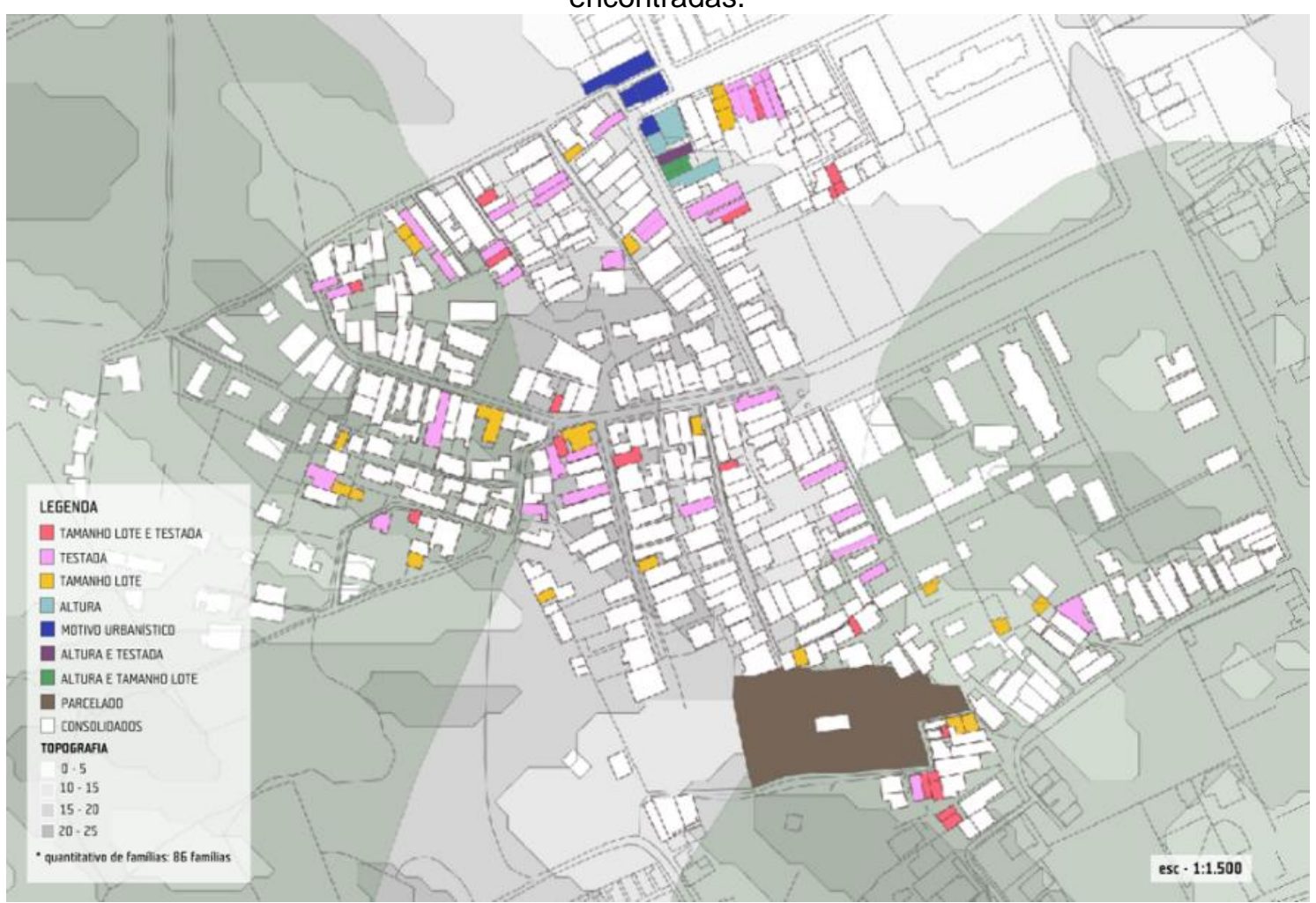

Fonte: LOPES FILHO et al. (2018)

Além das características habitacionais analisadas, outras questões foram consideradas na definição das casas a serem reassentadas, como famílias habitando em área de risco ou em área de proteção ambiental. Os alunos também utilizaram o QGIS para analisar fatores socioambientais e urbanísticos sobrepostos às análises das habitações, obtendo, assim, uma visão completa da comunidade e seu entorno. Todos esses fatores foram rebatidos no Plano de Urbanização e Regularização Fundiária produzido por cada equipe e, em seguida, considerados nas propostas de projetos urbanísticos, paisagísticos e arquitetônicos, prevendo espaços para as novas habitações, assim como a proteção das áreas ambientalmente frágeis.

Tendo em vista a praticidade proporcionada por softwares que utilizam a tecnologia SIG no desenvolvimento de mapas, um questionário de opinião foi aplicado para melhor compreender a percepção do aluno em relação à introdução do SIG ao conteúdo e à metodologia da disciplina de Ateliê VI. Por meio do questionário, buscou-se identificar os principais problemas a serem melhorados no semestre seguinte, uma vez que a monitoria acadêmica requer constante avaliação e aperfeiçoamento. Solicitou-se que os estudantes realizassem comentários sobre suas maiores dificuldades com o programa e seus principais ganhos no desenvolvimento dos trabalhos e na análise da comunidade estudada. $O$ questionário tratou ainda do conhecimento prévio da tecnologia SIG e se, na opinião do aluno, ela seria útil no futuro seu profissional. 


\section{Eteducitec \\ ISSN: 2446-774X}

Dentre as 28 respostas obtidas no questionário, 53,6\% dos alunos responderam que não conheciam e que nunca haviam utilizado o QGIS ou outro software que utilizasse a tecnologia SIG. Isso mostra que a tecnologia ainda é pouco difundida no âmbito acadêmico, apesar da existência de outras disciplinas relacionadas ao urbanismo dentro da grade curricular obrigatória do curso e nas quais a utilização do SIG serviria de auxílio no desenrolar dos trabalhos. Assim, muitos alunos tiveram dificuldade no uso do SIG durante a disciplina de Ateliê VI devido à pouca familiaridade, o que se somou ao desenvolvimento de trabalhos mais complexos do que estão habituados e que requerem muito tempo de análise.

Alguns estudantes relataram que aprender a utilizar a ferramenta, considerada complexa por exigir a especialização da mão de obra em seu uso profissional, exigiu a dedicação de muito tempo que poderia ter sido utilizado de outra forma na disciplina. No entanto, tal esforço significou ganho de tempo nas etapas de análise espacial e produção de mapas.

Apesar de todas as dificuldades encontradas pelos alunos, quando questionados se a utilização do QGIS contribuiu para a análise dos parâmetros e definição de quais unidades habitacionais seriam realocadas e quais permaneceriam, 100\% dos entrevistados responderam que sim. Com isso, confirma-se que o programa ajudou, principalmente, na visualização das ações a serem tomadas na etapa de plano, permitindo decisões mais coerentes com a realidade do local.

É relevante ressaltar, ainda, que muitas dessas decisões foram tomadas a partir de um banco de dados cujas informações foram levantadas através da análise de imagens de satélite disponíveis em softwares como o Google Earth e de bases cartográficas disponibilizadas para AutoCAD, que apresentam informações próximas à realidade, mas sem a devida precisão. A realização de levantamentos in loco dessas casas seria o meio mais apropriado para a obtenção de dados condizentes com a realidade. Porém, em razão das limitações desse tipo de trabalho dentro de uma disciplina de graduação com tempo restrito, não foi possível alcançar um maior aprofundamento em campo, como seria o mais adequado no caso de um projeto real de regularização urbanística e fundiária.

\section{Conclusão}

O uso da tecnologia SIG no contexto da disciplina de Ateliê VI contribuiu positivamente para o desenvolvimento da atividade de caracterização habitacional, o que se deu em decorrência da capacidade de sistematização de informações por meio do software QGIS. A partir da simulação de diversos cenários, obteve-se de forma mais eficiente e rápida a definição dos novos parâmetros urbanísticos para a área de estudo, contribuindo para 0 desenvolvimento do Plano de Urbanização e Regularização Fundiária. Todavia, os alunos encontraram alguns problemas decorrentes do uso e da sistematização de informações dentro do QGIS, sendo estes solucionados com o auxílio das professoras e monitoras da disciplina. 


\section{Educitec \\ ISSN: 2446-774X}

A introdução do uso dessa tecnologia na disciplina, uma novidade para mais da metade dos alunos, aconteceu com o objetivo de facilitar o desenvolvimento das atividades e otimizar o tempo do processo. Porém, verificou-se que muitas das informações adotadas não foram coletados em campo, o que se deve à complexidade do processo de levantamento de dados em campo no contexto de uma disciplina de graduação. Sendo assim, o preenchimento do banco de dados revela um resultado numérico da realidade estudada, porém não se atenta a todas as particularidades das habitações, desconsiderando questões como apropriação do lugar, pertencimento, ventilação natural, dentre outros aspectos que requerem aprofundamento em campo.

Entende-se que o SIG cumpre seu papel como uma ferramenta facilitadora na compreensão dos dados numéricos relativos aos parâmetros edilícios existentes em assentamentos precários, uma vez que softwares como o QGIS permitem a visualização e a transformação de números em formas de ocupação do solo. No entanto, é necessário que o aluno desenvolva a análise crítica sobre a área de estudo para além da leitura morfológica, o que se dá através de visitas à comunidade e do estudo do referencial teórico. Dessa forma, facilita-se a tomada de decisões de planejamento urbano mais próximas das reais necessidades locais.

Por fim, ressalta-se que a introdução de novas ferramentas didáticas trata-se de um processo contínuo de aprendizagem na relação entre alunos, monitores e professores. Assim, incentiva-se constantemente 0 aperfeiçoamento de metodologias auxiliadas por recursos tecnológicos, tais como o SIG, sendo esta ferramenta de grande importância para disciplinas de planejamento e projeto urbano.

\section{Referências}

ALFONSIN, B. M. Depois do Estatuto da Cidade: ordem jurídica e política urbana em disputa, Porto Alegre e o urbanizador social. Revista Brasileira de Estudos Urbanos e Regionais, São Paulo, v. 2, n. 7, p.47-59, nov. 2005.

BRASIL, A.; ALDIGUERI, C. Definição de novos parâmetros e índices de construção: exercício de simulação e aplicação em área de ZEIS. In: ENCONTRO DE PRÁTICAS DOCENTES UNIFOR, 4, 2014, Fortaleza. Anais... Fortaleza: UNIFOR, 2014. p. 1-12.

CARDOSO, A. L. Avanços e desafios na experiência brasileira da urbanização de favelas. Cadernos Metrópole, São Paulo, n. 17, p.219-240, 2007.

FEITOSA, A. Dez Zonas Especiais de Interesse Social serão regulamentadas. 0 Povo, Fortaleza, 29 mai. 2018. Disponível em: <https://www.opovo.com.br/jornal/cidades/2018/05/dez-zonas-especiais-deinteresse-social-serao-regulamentadas.html>. Acesso em: 24 ago. 2018.

FORTALEZA. Lei complementar n 62, de 2 de fevereiro de 2009. Plano Diretor Participativo de Fortaleza. Diário Oficial do Município, Fortaleza, CE, 13 mar. 2009. 
ISSN: $2446-774 X$

FORTALEZA. Fundação de Desenvolvimento Habitacional de Fortaleza (HABITAFOR). Plano Local de Habitação de Interesse Social de Fortaleza: Produto V. Fortaleza, 2013.

FREITAS, C. F. S.; LIMA, L. S. Cadastro Territorial e SIG no processo de regularização fundiária: o caso da ZEIS do Planalto Pici em Fortaleza, Ceará. In: SIMPÓSIO BRASILEIRO DE CIÊNCIAS GEODÉSICAS E TECNOLÓGICAS DA GEOINFORMAÇÃO, 4, 2012, Recife. Anais... Recife: UFPE, 2012. p. 1-8.

GONÇALVES, T. S.; FREITAS, C. F. S.; RIBEIRO, J. C. Regularização fundiária como instrumento de direito à moradia em Fortaleza: limitações de ordem urbanística. In: CONGRESSO INTERNACIONAL DE SUSTENTABILIDADE E HABITAÇÃO DE INTERESSE SOCIAL, 2, 2012, Porto Alegre. Anais... Porto Alegre: PUCRS, 2012. p. 1-11.

JACQUES, P. B. Estética das favelas. Vitruvius: Arquitextos, São Paulo, v. 2, n. 13, jun. 2001. Disponível em: <http://www.vitruvius.com.br/revistas/read/arquitextos/02.013/883>. Acesso em: 5 fev. 2019.

KLEINER, R. M.; MENEGUETTE, A. C. A. tecnologia dos Sistemas de Informações Geográficas (SIG) e a Internet. In: SIMPÓSIO BRASILEIRO DE GEOMÁTICA, 2, 2002, Presidente Prudente. Anais... Presidente Prudente: UNESP, 2002. p.357-364.

LISBOA FILHO, J.; IOCHPE, C. Introdução a sistemas de informações geográficas com ênfase em banco de dado. In: CONGRESSO DA SOCIEDADE BRASILEIRA DE COMPUTAÇÃO, 16, 1996, Recife. Anais... Recife: UFPE, 1996.

LOPES FILHO, A. W. S. et al. Planejando o Caça e Pesca. Trabalho desenvolvido para a disciplina de Ateliê VI do curso de Arquitetura e Urbanismo da Universidade de Fortaleza (UNIFOR). Fortaleza, 2018.

MARICATO, E. Metrópole, legislação e desigualdade. Estudos Avançados, São Paulo, v. 17, n. 48, p.151-167, ago. 2003.

MARICATO, E. O impasse da política urbana no Brasil. Petrópolis: Vozes, 2011. $219 \mathrm{p}$.

SOUZA, M. L. ABC do Desenvolvimento Urbano. Rio de Janeiro: Record, 2008. $190 \mathrm{p}$.

Submetido em 26/08/2018.

Aceito em 25/02/2019.

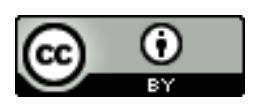

